\title{
Commentary on the preservation of human RBC, platelets, plasma clotting proteins and peripheral blood mononuclear hematopoietic stem cells by freezing and storage in a $80 \mathrm{C}$ mechanical freezer
}

\author{
C.R. Valeri* and G. R. Giorgio \\ NBRL, Inc., USA
}

\begin{abstract}
For the past 50 years, NBRL has evaluated the cryopreservation of RBC, platelets, peripheral blood pluripotential hematopoietic mononuclear adult stem cells, and plasma to treat military personnel subjected to traumatic injuries and those exposed to radiation injury.The research was funded by the US-Navy's Bureau of Medicine and Surgery, the Office of Naval Research and the Congress of the United States to provide frozen blood products to supplement the liquid preserved blood products.

NBRL has demonstrated that RBC preserved with $40 \% \mathrm{~W} / \mathrm{V}$ glycerol, platelets preserved with $6 \%$ DMSO, peripheral blood pluripotential hematopoietic mononuclear adult stem cells preserved with $10 \% \mathrm{DMSO}$ and plasma can all be frozen and stored in mechanical freezers at $-80^{\circ} \mathrm{C}$. RBC frozen with $40 \% \mathrm{~W} / \mathrm{V}$ glycerol can be stored at $-80^{\circ} \mathrm{C}$ for at least 21 years; platelets frozen with $6 \% \mathrm{DMSO}$ can be stored at $-80^{\circ} \mathrm{C}$ for at least 2 years; peripheral blood pluripotential hematopoietic mononuclear adult stem cells froze with $10 \% \mathrm{DMSO}$ can be stored at $-80^{\circ} \mathrm{C}$ for at least $1 \frac{1}{2}$ years; and fresh frozen plasma can be stored at $-80^{\circ} \mathrm{C}$ for at least 14 years.

The 15 -year experience by the Netherlands military has demonstrated that frozen red blood cells, frozen platelets, and frozen plasma all stored at $-80^{\circ} \mathrm{C}$ in mechanical freezers without the need for fresh whole blood and single donor apheresed platelets stored at room temperature with agitation provided blood products to successfully treat wounded casualties without any adverse events: 2,175 units of frozen RBC, 1,070 units of frozen platelets, 3,001 units of frozen plasma and 879 units of liquid preserved $\mathrm{RBC}$ stored at $4 \mathrm{C}$ were transfused to 1,011 casualties. The Netherlands military has demonstrated for the first time that frozen RBC, frozen platelets and fresh frozen plasma stored at $-80^{\circ} \mathrm{C}$ in mechanical freezers can be used to treat wounded casualties without the need for fresh whole blood and single donor platelets.
\end{abstract}

\section{Commentary}

The Naval Blood Research Laboratory, Boston, MA has been supported for the past 50 years by the U.S. Navy's Bureau of Medicine and Surgery, Naval Medical Research and Development Command, and the Office of Naval Research (ONR) to develop, test, and evaluate procedures to preserve blood and blood products to treat military and civilian personnel subjected to trauma and radiation injury. Human $\mathrm{RBC}$ have been successfully frozen at $-80^{\circ} \mathrm{C}$ for at least 21 years; human platelets have been successfully frozen for at least 2 years; human plasma has been successfully frozen at $-80^{\circ} \mathrm{C}$ for at least 14 years; and human peripheral blood mononuclear hematopoietic stem cells have been successfully frozen at $-80^{\circ} \mathrm{C}$ for at least $1^{1 / 2}$ years. The 50 year experience at the NBRL, Boston, MA has demonstrated that frozen red blood cell cells, frozen platelets, and frozen plasma can be used to successfully treat wounded casualties without any adverse events.

Extensive in vitro studies have been published together with in vivo studies in normal volunteers, patients with hematologic disorders, patients subjected to surgical procedures with and without cardiopulmonary bypass, and patients subjected to traumatic injuries [1-3]. In addition, studies were performed on dogs and baboons to assess the safety and therapeutic effectiveness of autologous and allogeneic blood products.During the past 50 years, the preservation of the safe and therapeutically effective viable and functional RBC, platelets, plasma clotting protein and peripheral blood mononuclear hematopoietic stem cells has been accomplished by freezing and storage in a $-80^{\circ} \mathrm{C}$ mechanical freezer.Storage of blood products in a $-80^{\circ} \mathrm{C}$ mechanical freezer produces a freezing rate of 2 to $3^{\circ} \mathrm{C}$ per minute.

Human RBC have been successfully frozen with $40 \%$ W/V glycerol at $-80^{\circ} \mathrm{C}$ for at least 21 years [4]; human platelets have been successfully frozen at $-80^{\circ} \mathrm{C}$ with $6 \%$ DMSO for at least 2 years $[5,6]$ human plasma has been successfully frozen at $-80^{\circ} \mathrm{C}$ for at least 14 years [7] and human peripheral blood mononuclear hematopoietic stem cells have been successfully frozen at $-80^{\circ} \mathrm{C}$ for at least $1 \frac{112}{2}$ years [8].

The freezing rate of $2-3^{\circ} \mathrm{C}$ per minute which occurs with the storage of platelets in a $-80^{\circ} \mathrm{C}$ mechanical freezer produces a bimodal population of human and baboon platelets. The bimodal population represents a population of platelets that circulates like platelets stored at room temperature and a population of platelets that functions shortly after transfusion like platelets stored at $4^{\circ} \mathrm{C}$ [9-12].

The procedures to freeze human RBC with $40 \% \mathrm{~W} / \mathrm{V}$ glycerol,

Correspondence to: C.R. Valeri, NBRL, Inc., 195 Bournehurst Drive, Plymouth, MA 02360, USA; E-mail: navblood@yahoo.com

Received: November 09, 2015; Accepted: December 01, 2015; Published: December 04, 2015 
Valeri CR (2015) Commentary on the preservation of human RBC, platelets, plasma clotting proteins and peripheral blood mononuclear hematopoietic stem cells by freezing and storage in a $80 \mathrm{C}$ mechanical freezer

platelets with $6 \%$ DMSO and peripheral blood mononuclear hematopoietic stem cells with $10 \%$ DMSO have been simplified by the removal of the supernatant glycerol prior to freezing of the red blood cells at $-80^{\circ} \mathrm{C}$; the removal of the supernatant DMSO prior to freezing the platelets at $-80^{\circ} \mathrm{C}$; and the removal of the supernatant DMSO prior to freezing of the peripheral blood mononuclear hematopoietic stem cells at $-80^{\circ} \mathrm{C}$.

The freezing of red blood cells containing $40 \% \mathrm{~W} / \mathrm{V}$ glycerol at $-80^{\circ} \mathrm{C}$, freezing of platelets containing $6 \% \mathrm{DMSO}$, and freezing of peripheral blood mononuclear hematopoietic stem cells containing $10 \%$ DMSO in a $-80^{\circ} \mathrm{C}$ mechanical freezer increases the number of units of frozen blood products that are stored at $-80^{\circ} \mathrm{C}$ in a mechanical freezer. The removal of the supernatant glycerol prior to freezing the glycerolized $\mathrm{RBC}$ reduces the volume of solution needed to deglycerolize the red blood cells.

The major event to simplify the washing of human RBC treatedwith $40 \% \mathrm{~W} / \mathrm{V}$ glycerol was the introduction in 1998 by Haemonetics Corporation, Braintree, MA of the Automated Cell Processor (ACP) 215 which is a functionally closed instrument to glycerolize and deglycerolize the red blood cells with storage in the additive solution AS-3 (Nutricel) at $4^{\circ} \mathrm{C}$ for 2 weeks which is an FDA approved procedure [13-15].

The sterile docking device and the Haemonetics Automated Cell Processor (ACP) 215 instrument are used to biochemically treat indated and outdated universal donor group $\mathrm{O}$ Rh positive and group $\mathrm{O} \mathrm{Rh}$ negative $\mathrm{RBC}$ with a solution containing pyruvate, inosine, phosphate and adenine (PIPA) with subsequent freezing and storage at $-80 \mathrm{C}$ followed by thawing, deglycerolization, and storage at $4^{\circ} \mathrm{C}$ in AS-3 (Nutricel) for at least 24 hours provide red blood cells with 24 hour posttransfusion survival of $75 \%$ with normal affinity for oxygen $[16,17]$. Universal donor group $\mathrm{O} \mathrm{Rh}$ positive and group $\mathrm{O} \mathrm{Rh}$ negative $\mathrm{RBC}$ treated with $40 \% \mathrm{~W} / \mathrm{V}$ glycerol and stored at $-80^{\circ} \mathrm{C}$ for at least 10 years, thawed and deglycerolized using the Haemonetics ACP215 instrument stored in AS-3 (Nutricel) at $4^{\circ} \mathrm{C}$ for 2 weeks have 24-hour posttransfusion survival of $75 \%$, moderately impaired oxygen transport function and less than $1 \%$ hemolysis[13,14]. The freezing of universal donor group $\mathrm{O} \mathrm{Rh}$ positive and group $\mathrm{O} \mathrm{Rh}$ negative red blood cells with $40 \% \mathrm{~W} / \mathrm{V}$ glycerol and frozen at $-80^{\circ} \mathrm{C}$ in mechanical freezers provide red blood cells which are viable and functional with less than $1 \%$ hemolysis and with residual total white blood cell count of $1 \times 10^{7}$ per unit, and less than 5\% residual plasma level [3].

In 1968, the U.S. Navy deployed -80 C water-cooled mechanical freezers in South Vietnam to freeze red blood cells to supplement fresh whole blood and liquid preserved whole blood to treat casualties. Since 2000 , the $-80^{\circ} \mathrm{C}$ air-cooled mechanical freezers have been deployed in combat zones in the Middle East by the Netherlands military under the direction of Dr. Charles Lelkens, Dr. FemkeNoorman, and Dr. John Badloe and their associates to freeze red blood cells, platelets and plasma all frozen and stored at $-80^{\circ} \mathrm{C}$ in mechanical freezers without the need for fresh whole blood to successfully treat both military and civilian casualties.

The freezing of human platelets treated with 6\% DMSO, the supernatant DMSO removed, and stored at $-80^{\circ} \mathrm{C}$ produce a bimodal population of platelets following thawing. One population of platelets that circulate is GpIb normal and reduced annexin $\mathrm{V}$ binding and the other population of platelets GpIb reduced and increased anenxin $\mathrm{V}$ binding does not circulate but function to reduce nonsurgical blood loss. The bimodal population of platelets and platelet microparticles are present in nonwashed platelets frozen after removal of the supernatant DMSO and in washed platelets frozen with the supernatant DMSO $[11,12]$.

Studies performed at NBRL over the past 50 years have demonstrated that the $-80^{\circ} \mathrm{C}$ mechanical freezer can preserve $\mathrm{RBC}$, platelets, peripheral blood hematopoietic mononuclear stem cells and plasma to supplement the liquid preserved blood products to treat patients subjected to hemorrhagic shock and radiation injury. The $-80^{\circ} \mathrm{C}$ temperature allows for shipment of these frozen blood products using insulated containers and dry ice. The $-80^{\circ} \mathrm{C}$ mechanical freezer allows for freezing of these blood products without the need for liquid nitrogen to control the rate of freezing at $1^{\circ} \mathrm{C}$ per minute $[18,19]$.

The FDA has approved the storage of RBC frozen with $40 \% \mathrm{~W} / \mathrm{V}$ glycerol at $-80^{\circ} \mathrm{C}$ for 10 years. The FDA has approved RBC with $40 \%$ $\mathrm{W} / \mathrm{V}$ glycerol, frozen at $-80^{\circ} \mathrm{C}$, and deglycerolized using the automated functionally closed Haemonetics ACP2 15 instrument for storage at $4^{\circ} \mathrm{C}$ in the additive solution A.S-3 (Nutricel) for 2 weeks [20]. FDA has not approved the use of single donor non-leukoreduced and leukoreduced group O platelets treated with 6\% DMSO, concentrated to remove the supernatant DMSO, frozen and stored at $-80^{\circ} \mathrm{C}$ for at least 2 years[5,6,11].FDA has approved the freezing and storage of plasma at $-80^{\circ} \mathrm{C}$ for 7 years.

Studies at the NBRL have shown that human RBC with $40 \% \mathrm{~W} / \mathrm{V}$ glycerol and stored at $-80^{\circ} \mathrm{C}$ tolerate fluctuations in temperature without adverse effects on in vitro and in vivo measurements [21-23].

The breakage of RBC containing $40 \% \mathrm{~W} / \mathrm{V}$ glycerol in polyvinylchloride plastic stored in rigid cardboard boxes is about $3 \%$ for non-transported units of RBC and about $6 \%$ for transported units of RBC [18,20,23-25].

Platelets are treated with 6\% DMSO and the supernatant DMSO removed prior to freezing and storage at $-80^{\circ} \mathrm{C}$. The thawed previously frozen platelets are diluted with 10 to $20 \mathrm{ml}$ of $0.9 \% \mathrm{NaCl}$ or a unit of thawed $\mathrm{AB}$ plasma prior to transfusion [11,26-28].

The important factors used in the freezing of platelets and mononuclear cells include:

DMSO as the FDA approved cryoprotectant, a final concentration of 5 or $6 \%$ DMSO for platelets and 10\% DMSO for mononuclear cells (MNC) $[12,27,28]$. The supernatant DMSO is removed prior to freezing the platelets and MNC.

The rate of freezing at 2-3 C per minute occurs by storage of the platelets and MNC in $300 \mathrm{ml}$ PVC plastic bags placed in polyester plastic bags and stored in rigid cardboard box with placement on the bottom of a $-80^{\circ} \mathrm{C}$ mechanical freezer $[11,18,19,26]$.

Liquid nitrogen is not needed for freezing or storage of platelets and MNC.Platelets with $6 \%$ DMSO can be stored at $-80^{\circ} \mathrm{C}$ for at least 2 years and MNC with $10 \%$ DMSO can be stored at $-80^{\circ} \mathrm{C}$ for $1 \frac{1 / 2}{2}$ years. Platelets and $\mathrm{MNC}$ do not have to be washed prior to transfusion $[11,18,20,27,28]$.

Automation of RBC glycerolization using the high separation bowl attached to the Haemonetics ACP215 disposable glycerolizing set has simplified glycerolization of both nonrejuvenated and rejuvenated RBC [15]. The procedure to deglycerolize RBC frozen with $40 \% \mathrm{~W} / \mathrm{V}$ glycerol using the ACP215 reduces the glycerol concentration to $<1 \%$, reduces the level of PIPA solution used to biochemically modify the $\mathrm{RBC}$ prior to freezing, reduces the WBC to a mean of $1 \times 10^{7}$ in the 
Valeri CR (2015) Commentary on the preservation of human RBC, platelets, plasma clotting proteins and peripheral blood mononuclear hematopoietic stem cells by freezing and storage in a $80 \mathrm{C}$ mechanical freezer

unit, and reduces the plasma level to less than $5 \%$ with less than $1 \%$ hemolysis [18].

Leukoreduced and washed deglycerolized $\mathrm{RBC}$ stored at $4^{\circ} \mathrm{C}$ in AS-3 for 2 weeks is the ideal RBC product to prevent transfusionrelated acute lung injury (TRALI) and systemic inflammatory response syndrome (SIRS) [18].

NBRL has simplified the RBC freezing by removing the supernatant glycerol prior to freezing. NBRL has simplified freezing of platelet and pluripotential mononuclear cells by removal of the supernatant DMSO prior to freezing.Removal of the supernatant DMSO removes about 95\% of the DMSO and eliminates the need for post-thaw washing prior to transfusion [18]. Lelkens CCM and associates have reported the use by the Netherlands military of Group O Rh positive and group O Rh negative RBC frozen with $40 \% \mathrm{~W} / \mathrm{V}$ glycerol and stored at $-80^{\circ} \mathrm{C}$; group O single donor leukoreduced platelets frozen with 5\% DMSO with removal of the supernatant DMSO solution before freezing and storage at $-80^{\circ} \mathrm{C}$ and following thawing resuspended in $\mathrm{AB}$ plasma; and $\mathrm{AB}$ plasma stored at $-30^{\circ} \mathrm{C}$ and then at $-80^{\circ} \mathrm{C}$ thawed and stored at $4^{\circ} \mathrm{C}$ for 7 daysto treat patients who required these blood products [26-28].

Lelkens CCM and associates experience in the Netherlands military has demonstrated for the first time that frozen $\mathrm{RBC}$, frozen platelets and frozen plasma stored at $-80^{\circ} \mathrm{C}$ can be used to treat patients without the need for a "walking blood bank" and fresh whole blood $[26,29,30]$. Henkelman and Rakhorst [31] have reported the safety and therapeutic effectiveness of frozen RBC, frozen platelets, and frozen plasma stored in $-80^{\circ} \mathrm{C}$ mechanical freezers to treat combat casualties without the need for fresh whole blood [32].

The Netherlands military has been actively freezing universal donor group $\mathrm{O} \mathrm{Rh}$ positive and group $\mathrm{O} \mathrm{Rh}$ negative $\mathrm{RBC}$, single donor leukoreduced frozen group $\mathrm{O}$ platelets and frozen $\mathrm{AB}$ plasma in $-80^{\circ} \mathrm{C}$ mechanical freezers. These frozen blood products have been collected from donors meeting FDA regulations that were safely transported and stored in $-80^{\circ} \mathrm{C}$ mechanical freezers without breakage. These blood products have been obtained from screened blood donors and tested for the mandated infectious disease markers prior to freezing and have eliminated the need for fresh whole blood or apheresedleukoreduced platelets stored at room temperature for 5 days with agitation to treat patients suffering traumatic injuries with therapeutically effective outcomes and without adverse events.

The utilization of the $-80^{\circ} \mathrm{C}$ mechanical freezers to freeze $\mathrm{RBC}$, platelets, and plasma by the Netherlands military has demonstrated the safety and therapeutic effectiveness of these frozen blood products without the need for fresh whole blood or apheresed platelets to treat military and civilian casualties requiring more than 10 units of red blood cells within a 24-hour period in combat zones in Afghanistan and Iraq. It is of interest that the Netherlands investigators pioneered the use of liquid nitrogen to freeze blood products but now utilize $-80^{\circ} \mathrm{C}$ mechanical freezers to freeze red blood cells, platelets and plasma to treat combat casualties.

Dr. John Badloe at the ATACCC meeting on August 16, 2010 at St. Pete, Florida reported that in Afghanistan from 2000 to 2010, 859 patients received 6,335 blood products which include 1918 units of frozen red blood cells, 841 units of liquid preserved red blood cells, 2560 units of frozen plasma and 1,016 units of frozen platelets with no transfusion reactions. Fresh whole blood was not used by the Netherlands military because the fresh whole blood could not be tested prior to transfusion for the mandated infectious disease markers whereas all the frozen blood products were tested for the mandated infectious disease markers prior to freezing from the donors who were screened prior to donation.

Dr. John Badloe reported the Netherlands military experience in the Middle East war zones using frozen blood products, i.e. frozen group $\mathrm{O}$ Rh positive and group $\mathrm{O}$ Rh negative $\mathrm{RBC}$, frozen $\mathrm{AB}$ plasma, and frozen group $\mathrm{O}$ single donor leukoreduced $2.5-3.0 \times 10^{11}$ platelets with removal of supernatant DMSO, all frozen and stored at $-80 \mathrm{C}$ in mechanical freezers at ratio of 1:1:1 increased survival of patients from $44 \%$ to $84 \%$. No adverse events were reported and only frozen blood products without the need for fresh whole blood were safe, available, effective and efficient in the treatment of patients requiring at least 10 units of red blood cells in a 24-hour period for resuscitation.

The abstract which was reported by Dr. John Badloe and Dr. Femke Noorman from the Ministry of Defense, Military Blood Bank, Leiden, Netherland at the Annual meeting of the AABB, San Diego, CA October 22-25, 2011 confirm the procedures provided by the NBRL, Boston, MA to freeze human RBC, plasma, and platelets in $-80^{\circ} \mathrm{C}$ mechanical freezers. This report by the Netherlands military demonstrates that fresh whole blood advocated by Colonel William Crosby and the U.S. Army is no longer used by the Netherlands military and the fresh whole blood can be replaced by frozen RBC, frozen plasma, and frozen platelets significantly improved survival of the massively transfused patients [30].

A comparison between the U.S. Army procedures and the Netherlands procedures to provide blood products to treat combat casualties needs to be performed regarding the logistic requirements, outdating of blood products, compatibility, cost of transportation, availability, safety and therapeutic effectiveness. The quality and quantity of the blood products to resuscitate casualties requiring at least 10 units of red blood cells in a 24-hour period and the mortality and morbidity utilizing the U.S. Army procedures to the Netherlands procedures in combat zones need to be compared. The Netherlands military has documented that $-80^{\circ} \mathrm{C}$ frozen red blood cells, plasma and platelets were deployable, available, compatible, safe and effective in the treatment of trauma patients with or without massive blood loss in military theatre.

Dr. Femke Noorman and Dr. John Badloe and associates presented one oral presentation and three (3) poster presentations at the AABB annual meeting from October 6-9, 2012 in Boston, MA. Studies can now be done to compare the safety and therapeutic effectiveness of universal donor RBC frozen for at least 10 years, group $\mathrm{O}$ platelets frozen for at least 2 years, and $\mathrm{AB}$ plasma frozen for at least 10 years (all blood products frozen and stored at $-80^{\circ} \mathrm{C}$ with a range of $-65^{\circ} \mathrm{C}$ to $-90^{\circ} \mathrm{C}$ ) without the need for fresh whole blood to the current use of fresh whole blood (FWB), liquid preserved $\mathrm{RBC}$ stored at $4^{\circ} \mathrm{C}$ in additive solutions for as long as 42 days, single donor leukoreducedapheresed platelets stored with agitation at room temperature for 5 days, and fresh frozen plasma and cryoprecipitate stored at $-20^{\circ} \mathrm{C}$ for one year on mortality and morbidity in the recipients.

In the study to compare the procedures utilized by the Netherlands military to the current FDA approved procedures to provide blood products; the volume and composition of the resuscitation fluids used with the blood products need to be reported [33]. The morbidity and mortality associated with the current FDA approved blood products can be compared to the use of frozen RBC, frozen platelets, and frozen plasma without the need for fresh whole blood and apheresed platelets which Netherlands military has successfully utilized to treat 
Valeri CR (2015) Commentary on the preservation of human RBC, platelets, plasma clotting proteins and peripheral blood mononuclear hematopoietic stem cells by freezing and storage in a $80 \mathrm{C}$ mechanical freezer

combat casualties in war zones from August 2006 to February 2012; 2,175 units of frozen RBC, 1,070 units of frozen platelets, 3,001 units of frozen plasma and 879 units of liquid preserved $\mathrm{RBC}$ stored at $4^{\circ} \mathrm{C}$ were transfused to 1,011 casualties without any transfusion reactions observed. The blood products were obtained from pre-screened donors and the blood products were tested for infectious diseases prior to freezing. The frozen red blood cells, plasma and platelets were available, compatible, safe and effective in the treatment of trauma patients with or without massive blood loss in military theatre [32].

In the response to the paper "Transfusion of older stored blood and risk of death" published by Wang et al. [34]an editorial was written by Warkentin and Eikelboom [35] "Old blood bad?Either the biggest issue in transfusion medicine or a nonevent" in Transfusion (52:1165-1167, 2012).These authors stated "the demonstration of an association (if indeed there is one) between the age of transfused blood and outcome would be useless if one could not do anything about it". This editorial failed to acknowledge that freeze preservation of red blood cells, platelets and plasma has been reported to provide safe and therapeutically effective blood products from 2006 to 2012 to successfully treat 1,011 civilian and military casualties in war zones in Iraq and Afghanistan by the Netherlands military using $-80^{\circ} \mathrm{C}$ mechanical freezers to freeze and store universal donor group $\mathrm{O} \mathrm{Rh}$ positive and group $\mathrm{O} \mathrm{Rh}$ negative red blood cells, single donor leukoreduced group $\mathrm{O}$ platelets, and group $\mathrm{AB}$ plasma without the need for fresh whole blood and apheresed platelets.

It is imperative that civilian and military blood banking communities change their methods of collection and preservation of blood products if they are really interested in providing patients with the safest and most therapeutically effective blood products and in avoiding risks associated with transfusion.

The 50 year experience at the NBRL, Boston, MA and the 15 year experience by the Netherlands military have demonstrated that frozen red blood cell cells, frozen platelets, and frozen plasma without the need for fresh whole blood and single donor platelets stored at room temperature with agitation provided blood products to successfully treat wounded casualties without any adverse events. The $-80^{\circ} \mathrm{C}$ mechanical freezer is needed to provide the safe and therapeutically effective frozen $\mathrm{RBC}$, frozen platelets and frozen plasma clotting proteins to treat patients without any adverse events. The $-80^{\circ} \mathrm{C}$ mechanical freezer eliminates the need for fresh whole blood, liquid preserved red blood cells stored at $4^{\circ} \mathrm{C}$, platelets stored at $22^{\circ} \mathrm{C}$ with agitation, and fresh frozen plasma and cryoprecipitate stored at $-20^{\circ} \mathrm{C}[3]$.

The reluctance of the blood banking community to consider any changes that could improve the safety and therapeutic effectiveness of blood products brings to mind two very relevant quotations:one by Maurice Maeterlinck is that "At every crossway on the road that leads to the future, every progressive spirit is opposed by a thousand men appointed to guard the past". The other by Winston Churchill is that "Occasionally man will stumble on the truth but will manage to pick himself up and continue on as if nothing had happened."It is time now to investigate the current blood banking procedures and to seek ways to improve them.

\section{References}

1. Valeri CR (1976) Blood Banking and the Use of Frozen Blood Products, Chemical Rubber Compnay, Boca Raton, Florida.

2. Valeri CR, Altschule MD (1981) Hypovolemic Anemia of Trauma. The Missing Blood Syndrome. Chemical Rubber Company Press, Boca Raton, Florida.

3. Valeri CR, Ragno Giorgio G (2013) Forty-five years of research at the NBRL, Boston,
Massachusetts. Chaotic observations, serendipity, and patience. Lulu Publishing Services.

4. Valeri CR, Pivacek LE, Gray AD, Cassidy GP, Leavy ME, et al. (1989) The safety and therapeutic effectiveness of human red cells stored at $-80 \mathrm{C}$ for as long as 21 years. Transfusion 29: 429-437. [Crossref]

5. Melaragno AJ, Carciero R, Feingold H, Talarico L, Weintraub L, et al. (1985) Cryopreservation of human platelets using $6 \%$ dimethylsulfoxide and storage at $-80^{\circ} \mathrm{C}$. Effects of 2 years of frozen storage at $-80^{\circ} \mathrm{C}$ and transportation in dry ice. Vox Sang 49: 245-258. [Crossref]

6. Valeri CR, Srey R, Lane JP, Ragno G (2003) Effect of WBC reduction and storage temperature on PLTs frozen with 6 percent DMSO for as long as 3 years. Transfusion 43: 1162-1167. [Crossref]

7. Valeri CR, Ragno G (2005)The effect of storage of fresh frozen plasma at $-80 \mathrm{C}$ for as long as 14 years on plasma clotting proteins. Transfusion 45: 1829-1830. [Crossref]

8. Valeri CR, Pivacek LE (1996) Effects of the temperature, the duration of frozen storage, and the freezing container on in vitro measurements in human peripheral blood mononuclear cells. Transfusion 36: 303-308. [Crossref]

9. Valeri CR (1974) Hemostatic effectiveness of liquid preserved and previously frozen human platelets. $N$ Engl J Med 290: 353-158. [Crossref]

10. Barnard MR, MacGregor H, Ragno G, Pivacek LE, Khuri SF, et al. (1999) Fresh, liquidpreserved, and cryopreserved platelets: adhesive surface receptors and membrane procoagulant activity. Transfusion 39: 880-888. [Crossref]

11. Valeri CR, Ragno G, Khuri S (2005) Freezing human platelets using 6\% DMSO with removal of the supernatant solution prior to freezing and storage at $-80 \mathrm{C}$ without postthaw processing. Transfusion 45: 1890-1898.

12. Valeri CR, Khuri S, Ragno G (2007) Non-surgical bleeding diathesis in anemic thrombocytopenic patients: Role of temperature, RBC, platelets, and plasma clotting proteins. Transfusion 47:206S-248S. [Crossref]

13. Valeri CR, Ragno G, Pivacek LE, Srey R, Hess JR, et al. (2001) A multicenter study of in vitro and in vivo values in human RBCs frozen with 40-percent (wt/vol) glycerol and stored after deglycerolization for 15 days at $4 \mathrm{C}$ in AS-3: assessment of RBC processing in the ACP 215. Transfusion 41: 933-939. [Crossref]

14. Valeri CR, Ragno G, Pivacek LE, O’Neill EM (2001) In vivo survival of apheresis RBCs, frozen with 40-percent (wt/vol) glycerol, deglycerolized in the ACP 215, and stored at 4 C in AS-3 for up to 21 days. Transfusion 41: 928-932. [Crossref]

15. Valeri CR, Ragno G, van Houten P, Rose L, Rose M, et al. (2005) Automation of the glycerolization of red blood cells with the high-separation bowl in the Haemonetics ACP215 instrument. Transfusion 45:1621-1627. [Crossref]

16. Valeri CR (1982) Use of rejuvenation solutions in red blood cell preservation. CRC Crit Rev Clin Lab Sci 17: 299-374.

17. Ragno G, Valeri CR (2006) Salvaging of liquid preserved O-positive and O-negative red blood cells by rejuvenation and freezing. Trans Aph Sci 35: 137-143. [Crossref]

18. Valeri CR, Ragno G (2006) Cryopreservation of human blood products. Trans Apher Sci 34: 271-287, with an editorial on pages 267-269.

19. McCullough J, Haley R, Clay M, Hubel A, Lindgren B, et al. (2010) Long-term storage of peripheral blood stem cells frozen and stored with a conventional liquid nitrogen technique compared with cells frozen and stored in a mechanical freezer. Transfusion 50: 808-819. [Crossref]

20. Valeri CR, Ragno G (2010) An approach to prevent the severe adverse events associated with transfusion of FDA-approved blood products. Trans Aph Sci 42: 223233. [Crossref]

21. Valeri CR, Valeri DA, Anastasi J, Vecchione JJ, Dennis RC, et al. (1981) Freezing in the primary polyvinylchloride plastic collection bag: A new system for preparing and freezing nonrejuvenated and rejuvenated red blood cells. Transfusion 21: 138-149. [Crossref]

22. Valeri CR, Sims KL, Bates JF, Reichman D, Lindberg JR, et al. (1983) An integrated liquid-frozen blood banking system. Vox Sang 45: 25-39. [Crossref]

23. Valeri CR, Pivacek LE, Cassidy GP, Ragno G (2001) In vitro and in vivo measurements of human RBCs frozen with glycerol and subjected to various storage temperatures before deglycerolization and storage at $4^{\circ} \mathrm{C}$ for 3 days. Transfusion 41: 401-405. [Crossref]

24. Valeri CR, Ragno G (2005) Breakage rate for RBC frozen with $40 \% \mathrm{~W} / \mathrm{V}$ glycerol in 800 mlpolyvinylchloride (PVC) plastic bags stored in rigid cardboard boxes at $-80^{\circ} \mathrm{C}$. Transfusion 45: 822-3. [Crossref] 
Valeri CR (2015) Commentary on the preservation of human RBC, platelets, plasma clotting proteins and peripheral blood mononuclear hematopoietic stem cells by freezing and storage in a $80 \mathrm{C}$ mechanical freezer

25. Valeri CR, Lane J, Srey R, Ragno G (2003) Incidence of breakage of human RBCs frozen with 40 percent wt/vol glycerol using two different methods for storage at $-80 \mathrm{C}$. Transfusion 43: 411-414. [Crossref]

26. Lelkens CC, Koning JG, de Kort B, Floot IB, Noorman F, et al. (2006) Experiences with frozen blood products in the Netherlands military. Transfus Apher Sci 34: 289298. [Crossref]

27. Noorman F, Badloe JF (2012) -80 C frozen platelets - efficient logistics, available, compatible,safe and effective in the treatment of trauma patients with or without massive blood loss in military theatre. AABB Oct 2012, Transfusion practice/clinical case studies, S53-030H, oral presentation. Transfusion 52: S53-030H, 33A

28. Noorman F, Strelitsid R, Badloe JF (2012)-80 C frozen platelets are activated compared to 24 hour liquid stored platelets and quality of frozen platelets is unaffected by a quick preparation method $(15 \mathrm{~min})$ which can be used to prepare platelets for the early treatment of trauma patients in military theatre. AABB Oct 2012, Components and component processing: platelets; SP23, Poster presentation. Transfusion 52: SP23, 62A.

29. Noorman F, et al. (2009) Frozen $-80 \mathrm{C}$ red cells, plasma and platelets in combat casualty care. Transfusion Suppl 49: 28A.
30. Badloe J, Noorman F (2011) The Netherlands experience with frozen $-80 \mathrm{C}$ red cells, plasma and platelets in combat casualty care S1-301. Transfusion Suppl 51.

31. Henkelman S, Rakhorst G (2012) Does modern combat still need fresh whole blood transfusions. Transfusion 52: 2272-2273. [Crossref]

32. Noorman F, Badloe JF (2012) -80 C frozen red blood cells, plasma and platelets efficientlogistics, available, compatible, safe and effective in the treatment of trauma patients with or without massive blood loss in military theatre. AABB Oct 2012 , Transfusion practice/clinical case studies: transfusion practices in emergent settings; SP383; poster presentation. Transfusion 52: SP383, 198A.

33. Valeri CR, Veech RL (2012) The unrecognized effects of the volume and composition of the resuscitation fluid used during the administration of blood products. Trans Aph Sci 46: 121-123. [Crossref]

34. Wang D, Sun J, Solomon SB, Klein HG, Natanson C (2012) Transfusion of older stored blood and risk of death: a meta-analysis. Transfusion 52: 1184-1195.

35. Warkentin TE, Eikelboom JW (2012) Old blood bad? Either the biggest issue in transfusion medicine or a nonevent. Transfusion 52: 1165-1167.

Copyright: $\odot 2015$ Valeri CR. This is an open-access article distributed under the terms of the Creative Commons Attribution License, which permits unrestricted use, distribution, and reproduction in any medium, provided the original author and source are credited. 